Review Article / Derleme Makale

\title{
Diagnostic Tests in The Management of Allergic Diseases in Primary Care
}

\section{Birinci Basamakta Alerjik Hastalıkların Yönetiminde Tanısal Testler}

Merve Uygunsoy ${ }^{* 1}$, Vildan Mevsim ${ }^{1}$

\begin{abstract}
Allergic diseases are a major cause of morbidity worldwide and cause a significant burden on the health and medical systems of both developed and developing economies. Most of the patients who want to get medical advice for allergic diseases firstly apply to the primary care. Most patients with allergies can be managed in primary care with appropriate treatment, advice and prevention, without the need for identification of the causative allergen. In the diagnosis of allergic diseases, first of all, a good medical history should be taken and physical examination should be performed. Allergy testing may be required if the patient's symptoms do not settle through medical treatment, or if the determination of the allergen will benefit the treatment of the patient.
\end{abstract}

Key words: Allergy, primary care, diagnostic test

\section{ÖZET}

Alerjik hastalıklar dünya çapında önemli bir morbidite nedenidir ve hem gelişmiş hem de gelişmekte olan ekonomilerin sağlık ve tıbbi sistemlerine önemli bir yük oluşturmaktadır. Alerjik hastalıklar için tıbbi tavsiye almak isteyen hastaların çoğunluğu öncelikle birinci basamağa başvurmaktadır. Alerjisi olan çoğu hasta, uygun tedavi, tavsiye ve korunma yöntemleriyle, etken alerjenin tanımlanmasına gerek kalmaksızın, birinci basamakta yönetilebilir. Alerjik hastalıkların yönetiminde öncelikle iyi bir öykü alınmalı ve fizik muayene yapılmalıdır. Eğer, medikal tedavi ile hastanın semptomları geçmezse veya alerjenin saptanmasının hastanın tedavisine fayda sağlayacağı düşünülürse, alerji testleri yapılması gerekebilir.

Anahtar kelimeler: Alerji, birinci basamak, tanı testleri

Received date / Geliş tarihi: 12.07.2019, Accepted date / Kabul tarihi: 10.11.2019

${ }^{1}$ Dokuz Eylül University, Department of Family Medicine, İzmir-TÜRKİYE.

*Address for Correspondence / Yazışma Adresi: Merve Uygunsoy, Dokuz Eylül University, Department of Family Medicine, İzmir-TÜRKIYYE.

E-mail: merveuygunsoy@gmail.com

Uygunsoy M, Mevsim V. Birinci Basamakta Alerjik Hastalıkların Yönetiminde Tanısal Testler TJFMPC, 2020;14 (1). 141-146

DOI: $10.21763 / \mathrm{tjfmpc} .693160$ 


\section{GíRiș}

Alerjik hastalıklar dünya çapında önemli bir morbidite nedenidir ve hem gelişmiş hem de gelişmekte olan ekonomilerin sağlık sistemlerine önemli bir yük oluşturmaktadır. Astım, rinosinüzit, atopik dermatit ve hayatı tehdit eden gıda, ilaç alerjileri, böcek 1sırığı alerjileri de dahil olmak üzere alerjiler toplumun en az \%30'unu ve ailelerin yaklaşık \%80'ini etkiler. ${ }^{1}$

2008 yılında yapılan Türkiye'de Alerjilerin Prevalansı ve Risk Faktörleri (PARFAIT) çalışmasındakırsal alanlarda astım, hırıltılı solunum, alerjik rinit ve egzema prevalans1 erkeklerde sirasiyla $\% 8,5, \% 13,5, \% 17,5$ ve $\% 10,8$ ve kadınlarda: $\% 11,2, \% 14,7, \% 21,2$ ve $\% 13,1$ idi. Kentsel alanlarda bunun karşılığı olan prevalans değerleri erkeklerde $\% 6,2, \% 10,8, \% 11,7$ ve $\% 6,6$ ve kadınlarda $\% 7,5, \% 12, \% 17$ ve $\% 7,3$ idi. Allerji prevalansının büyüklüğü nedeniyle alerji, bulaşıcı olmayan hastalıklar çerçevesinde büyük bir halk sağlığı sorunu olarak görülmelidir. ${ }^{2}$

Birçok ülkede uzman alerji hizmeti veren kuruluşlar bulunmamaktadır. $\mathrm{Bu}$ nedenle, alerji alanında çalışan büyük organizasyonlar (American Academy of Allergy, Asthma and Immunology, AAAAI; American College of Allergy, Asthma, and Immunology, ACAAI; European Academy of Allergy, Asthma and Clinical Immunology, EAACI; and the World Allergy Organization, WAO), alerjik hastalıkların önemi ve etkisi hakkında, sağlık çalışanlarının ve halkın eğitilmesinin teşvik edilmesi gerektiğini düşünmektedir. ${ }^{1}$

Alerjik hastalıklar için tıbbi tavsiye almak isteyen hastaların çoğunluğu öncelikle birinci basamağa başvurmaktadır. ${ }^{3}$

Alerjik hastalıkların çoğunluğu birinci basamak hekimleri tarafindan yönetildiğinden, birinci basamaktaki alerjik hastalık yönetim standard1, hastalığın önlenmesi ve kontrolü, hastaların yaşam kalitesi ve hasta memnuniyeti üzerinde güçlü bir etkiye sahiptir. ${ }^{4}$

Aile hekimlerinin alerjik hastalıklar konusunda farkındalık ve bilgi eksikliği, birinci basamakta görülen çok çeşitli hastalıkların arasında alerjik bulgu ve belirtilerin gözden kaçabilmesine, hastaların gerek olmadığı halde ikinci basamağa sevk edilmelerine, hastaların gereksiz IgE testi taleplerine neden olmaktadır. ${ }^{4}$

Alerjisi olan hastaların çoğunluğu, birinci basamakta, alerjeni spesifik olarak tanımlamak gerekmeden, uygun ilaç tedavisi ve tavsiyelerle yönetilebilir. Eğer tıbbi tedavi, semptomları kontrol etmekte yetersizse ve alerjenleri tanımlamanın hastanın tedavisine fayda sağlayacağ1 düşünülüyorsa, bazı durumlar için alerji testi yap1labilir. 5

Deri prick testi (DPT) astım, alerjik rinit veya diğer alerjik hastalık gelişme riski taşıyanların erken saptanması için önemlidir. Gıda alerjen duyarlılığının erken tespiti, hastada gıdayla ilişkili anafilaksi gelişme riskini azaltır. Deri prick testi sonuçları hemen alınabildiğinden, doktor hastaya belirli alerjenden kaçınma ve tedavi hakkında eğitim verebilir. ${ }^{6}$ Deri testinde saptanan duyarlılığın ko-sensitizasyon mu yoksa çapraz reaksiyon mu olduğunu anlamak amacıyla karşılaştırma testi gibi major ve minör alerjen moleküle karşı spesifik IgE ölçümlerinin de yol gösterici olabileceği bildirilmektedir. $^{7}$

\section{Alerjide Birinci Basamakta Kullanılabilecek Tanisal Testler}

Şu anda aeroallerjen (hava kaynaklı) alerjisi tanısı için tek bir altın standart test bulunmamaktadır.

Gıda alerjileri için altın standart olarak kabul edilen çift kör, plasebo kontrollü besin yama testinin, eğitimli alerji uzmanları tarafindan uygulanması gerektiğinden, kullanımı sınırlıdır. Bu testlerde şiddetli alerjik reaksiyon gelişme riski yüksektir ve testlerin uygulanması uzun zaman alır. Alerji testleri, her zaman klinik alerjiye eşdeğer olmayan, sensitizasyon (duyarlılaşma) hakkında bilgi verir, bu yüzden klinik öykünün doğru yorumlanması önemlidir. Klinik öykü, test için hangi alerjenlerin seçilmesi gerektiği konusunda, klinisyeni yönlendirir. Alerji tanısal testlerinin pratik değeri, doğrulayıcı bir araç kullanıldığında kesin ve tutarlı sonuçlar verebilme yeteneklerine dayanır. Öncellikle klinik öykü, doktorları alerjik hastalık tanısına yönlendirir. Alerji testi sonuçları, hastanın klinik tablosu, yaşı, ilgili alerjen maruziyeti ve test performans ölçütleri (örn. duyarlılık, özgüllük, tekrarlanabilirlik) ile birlikte yorumlanmalidır. ${ }^{8}$

Klinik semptomları olmayan hastalarda alerji testleri yapılması önerilmez. Semptomatik hastaların, hangi alerjenlerden kaçınması gerektiğini belirlemek için spesifik $\operatorname{IgE}$ testi yapılabilir. ${ }^{9}$ Öyküde, semptomların tipi, şiddeti ve süresi, semptomların başlangıcı ve maruz kalındığı varsayılan alerjene göre değişip değişmediği, semptomların yer, zaman (gün, mevsim), iş veya hobileri ile ilişkisi, hastanın semptomlara neden olabileceğini düşündüğü alerjenler, kişisel ve aile atopi öyküsü, yeni yiyeceklere, evcil hayvanlara veya bitkilere maruziyet, tüm reçetesiz tedaviler dahil olmak üzere, alınan tüm ilaçlar ve kullandığı 
alternatif ve tamamlayıc tedaviler sorgulanmalidir. ${ }^{10,11}$

\section{Deri Prick Testi (In vivo)}

Prik test yöntemi 1924'te Lewis ve Grant tarafından tanımlanmıştır. Prick testleri aeroalerjenlere, besinlere ve ilaçlara karşı ciltte oluşan tip 1 alerjik reaksiyonları ortaya çıkarmak için kullanılır. ${ }^{12}$

Deri prick testi (DPT) birçok sebepten ötürü alerjik yanıtı değerlendirmek için birincil test olarak kullanılmaktadır. İnvaziv olup doğru yapıldığında iyi tekrarlanabilirliğe sahiptir. Test sonuçları, test uygulamasından 15 dakika sonra değerlendirilebilir. Cilt testi kolayca ölçülebilir ve bir seansta çoklu alerjenlerin değerlendirilmesine izin verir. Hem yanlış pozitif hem de yanlış negatif sonuçlar, ara sıra meydana gelse de, deri testlerinin sonuçları (konjunktival, nazal veya bronşiyal alerjen testleri) ile iyi bir korelasyonu vardır. Ciddi egzamas1, dermografizmi olan, birinci nesil antihistaminik veya trisiklik antidepresan gibi antihistaminik aktivitesi olan ilaçlar kullanan hastalarda tanıda, serum spesifik IgE kullanılması uygundur. 8,9

Deri prick testleri ucuz, kolay uygulanabilir, güvenilir, hassastır ve anında sonuçları alma avantajına sahiptir. Anaflaksi gelişme riski oldukça düşüktür, test odasında veya hastanın başucunda yapılması güvenlidir. Dünya çapında, deri prick testi, kolaylık ve maliyet etkinliği nedeniyle tercih edilen bir test olmaya devam etmektedir. ${ }^{6}$

Amerika'da yapılmış 5 yıllık bir çalışmada, deri prick testi hiçbir ölümcül komplikasyona yol açmamıştır. ${ }^{13}$ Ancak, daha önce DPT ile ilişkili sistemik alerjik reaksiyonlar ve nadir ölümler meydana geldiğinden, ${ }^{14,15}$ bu tür testler uygulandığında bir doktor veya diğer sağlık çalışanları ve acil durum ekipmanı hazır bulunmalıdır. Deri prick testi ile ilişkili sistemik reaksiyonlar genelde 30 dakika içinde gerçekleşir. Sistemik alerjik reaksiyonlar genellikle anafilaksinin başlangıcı ile ilişkili bir gıda veya ilaç için test yaparken gelişir. Solunum yolu alerjenleriyle ilişkili sistemik reaksiyon gelişmesi çok olası değildir. Semptomatik astım tanılı hastalar, DPT astım alevlenmesi için bir risk faktörü olabilir. ${ }^{16}$

Beta blokör ve ACE inhibitörü kullanan hastalarda, sistemik reaksiyon gelişmesi durumunda, tedavide kullanılan epinefrine yanıt azalacağından, bu hastalar daha yüksek risk altındadır. Kanser, böbrek yetmezliği gibi kronik hastalığ ${ }_{1}$ olanlarda cilt testi reaktivitesi azalabilir. Benzer şekilde, gebelerde uterin kontraksiyonlara yol açabileceğinden, epinefrin kullanımı önerilmediğinden, DPT yapılması önerilmez. ${ }^{16}$ Alerjik semptomu olup ilgili alerjenin yoğun bulunduğu mevsimlerde deri testi yapılacaksa daha dikkatli olmak gerekir. ${ }^{7}$

“Deri Prick Testiyle İlgili Önemli Konular;

- Her hastaya "bilgilendirme ve onam formu" okutulup imzalatılmalıdır.

- Alerjik yakınmaların yoğun olduğu durumlarda (dinlemekle akciğerlerde yaygın wheezing, şiddetli burun tıkanıklığı, burun akıntısı, yorgunluk, vb.) ve ateşli hastalık varlığında test yapılmamalıdır.

- Gebelere DPT uygulanmamalıdır.

- DPT için yaygın kabul gören bir yaş sınırı yoktur. Bebeklik döneminde gerekmedikçe yapılmaz. Bebeklik ve yaşlılık dönemlerinde alerjenlere karşı deri reaktiviteleri daha düşüktür. Bazı durumlarda bebeklerde 2-3 adet temel alerjenle (ev tozu akarı, mantar sporu, vb.) uygulanabilir.

- Klasik antihistaminiklerin kullanımı en az üç gün önce; uzun etkili antihistaminlerin, trisiklik antidepresanların ve fenotiyazin türevlerinin kullanımı en az yedi gün önce kesilmelidir. Sistemik steroid kullanımının deri reaktivitesini azaltabileceği de unutulmamalıdır.

- DPT uygulanırken anafilaksi ya da yaygın ürtikeryal reaksiyon gelişme olasılığ denecek kadar düşüktür. Yine de işlem, sistemik bir anafilaktik reaksiyona uygun girişimlerde bulunulabilecek donanımı olan ortamlarda, doktor tarafindan ya da doktor gözetiminde uygulanmalı; test odasında mutlaka tansiyon aleti, oksijen tüpü ve maskesi, laringeal tüp, enjektör, intra-venözset ve solüsyonlar, adrenalin ampul, antihistamin ampul, kortikosteroid ampul ve salbutamol inhaler bulunmalıdır.

- Bazı durumlarda besinlerle doğrudan "prick" test yapılabilir. Pulpalı taze meyve ve sebzelere lanset batırıldiktan hemen sonra deriye uygulanır. Bu yöntem, taze "prick" test ya da "prick-by-prick" olarak bilinir ve pozitif prediktif değeri, genellikle ticari preparatlarla uygulanan besin "prick" testlerinden daha yüksektir. Yine, diğer bazı besinler ezilip belli oranlarda serum fizyolojikile seyreltilerek DPT için kullanılabilir. Ancak, bu yöntemlerde uygulanan alerjen miktarı belli olmadığı ve standardize edilemediği için, özellikle 
duyarlılığ1 yüksek kişilerde ve küçük çocuklarda, sistemik anafilaksi gelişme riski vardır. Besinlerle doğrudan yapılan "prick" testler, yalnızca bu konuda deneyimli uzmanlarca yapilmalı, rutin olarak uygulanmamalıdır.

- Bazen deri testinden 1-2 saat sonra başlayıp, 612 saatte en yüksek değerine ulaşan ve 24-48 saat içinde gerileyen geç reaksiyonlar olabilir. Bunların klinik önemi tartışmalıdır. "17

\section{Deri Prick Testinin Uygulanması}

Her bir alerjen ekstresinin yeri, test sonuçlarını doğru bir şekilde tanımlamak için bir kalemle ön kola işaretlenmelidir. Testler ön kolun ön yüzüne, bilek ve ante-kubital fossanın en az $2-3 \mathrm{~cm}$ üstünde sonlanacak şekilde uygulanmalıdır. DPT özellikle infantlarda ön kolun arka yüzüne de uygulanabilir ancak arka yüzde cilt daha hassas olduğundan, lezyonların (kabarıklıkların) daha büyük olabileceği, test sonuçları değerlendirilirken göz önüne alınmalıdır. ${ }^{16}$

İki deri prick testi arasındaki mesafenin $2 \mathrm{~cm}$ 'den fazla olmas1, kontaminasyon ve akson refleksine bağlı yalancı pozitiflikleri engellemek açısından kritik öneme sahiptir. ${ }^{18}$ Her alerjen ekstresinden bir damla sırayla ciltte işaretlenmiş yerlere damlatılır ve hemen ardından tek başlı metal lansetle delinir. ${ }^{19}$ Lanset her prick testi için önce alerjen ekstresine ardından da aynı basınçla, en az bir saniye cilde bastırılır. Epitel doku kanamaya sebep olmayacak şekilde delinmelidir. Kanama, yanlış pozitif sonuçlara neden olabilir. Kontaminasyona sebep olmamak için her bir prick alerjen ekstresi için yeni bir lanset kullanılmalıdır. Ciltte kalan fazla alerjen ekstresi gerekirse temiz bir peçete ile silinebilir ancak bunu yaparken kontaminasyondan kaçınılmalıdır. Histamin ve negatif kontrol test sonuçları da dahil olmak üzere tüm testlerin, uygulamadan 15-20 dakika sonra okunması için alarmlı bir zamanlayıcı kullanılmalıdır. Histamin testi 8-10 dakikada pozitifleşebilir. $^{20}$

Farklı üreticilerin, aynı alerjene için ürettikleri ekstreleriyle yapılan DPT sonuçları farklı olabilir. ${ }^{21}$ $\mathrm{Bu}$ yüzden DPT sonuçları karşılaştırılırken, aynı üreticiden alınan testler kullanılmalıdır.

\section{Deri Prick Testinin Yorumlanması}

Öncelikle pozitif ve negatif kontroller ölçülmelidir. Dermografizm varlığında negatif kontrolü yorumlamak zor olabilir. Histamin kontrolü, test materyallerinin doğru uygulandığından emin olmak ve test öncesi alınmış olabilecek potansiyel ilaçların etkileyebileceği negatif DPT sonuçlarını dışlamak için pozitif olmalıdır. Test uygulandıktan
15 dakika sonra, ciltteki her maddenin uygulandığ 1 yerde oluşan kabarıklığın çapı ölçülür. 3 mm'nin üzeri pozitif olarak yorumlanır. ${ }^{22}$

Sadece kabarıklığın çapının ölçülmesi (çevredeki eritemin çapının ölçülmemesi) testin tekrarlanabilirliğini arttırır. ${ }^{23}$ Ciltte oluşan kabarıklığın çapının büyüklüğü, o maddeye karşı oluşan desensitizayonun derecesini göstermez. Histamin reaksiyonunun büyüklüğü, kişiden kişiye farklılık gösterebilir ve bu alerjenlere karşı gelişen reaktiviteden bağımsızdır. Deri prick testleri sonuçları, histamine bağlı oluşan lezyonun büyüklüğüyle ilişkilendirilmemelidir.

DPT belirli alerjenlere karşı sensitizasyonu gösterir ancak sonuçları tıbbi öykü ve klinik semptomlara dayanarak yorumlanmalıdır. DPT, inhalan alerjileri teşhis etmek için çok özgül (\% 7095) ve duyarlıdır (\% $\%$ 80-97). ${ }^{24}$ Sadece klinik geçmişe dayanarak alerjik rinit teşhisinin pozitif prediktif değeri persistan alerji için \% 77 ve aralıklı mevsimsel alerji için \% 82-85'tir. DPT kullanılırsa bu oran \% 97-99'a çıkar. ${ }^{25}$

Deri prick testinin besin alerjenleri için özgüllük ve duyarlılığı daha düşüktür, ilaç alerjisi için özgüllük ve duyarlılığ bağlıdır. Çoğu durumda, pozitif bir DPT ilaç alerjisini çok muhtemel kılar; ancak negatif bir sonuç hastanın ilaç alerjisi olmadığını göstermez. Şüpheli böcek zehri alerjisi için, intradermal testler duyarlılı̆̆ 1 tespit etmede birincil moddur. Deri prick testi intradermal testten önce yapılır. ${ }^{16}$

\section{Alerjene Özgü IgE (In vitro)}

Serum alerjene özgü IgE testi (RAST testi), derideki mast hücrelerine bağlı antijene özgü IgE'nin aksine serumda serbest antijene özgü IgE'yi tespit eder. ${ }^{5}$ Serumda alerjene özgü (spesifik) IgE ölçümü, alerjinin teşhisine yardımcı olan önemli bir araçtır. Spesifik IgE endikasyonları DPT ile aynıdır. Testin duyarlılığı, genellikle DPT'den yüksektir, ancak daha düşük özgüllük gösterir ve bu nedenle DPT'leri güvenilir sonuçlar vermediğinde tercih edilir. ${ }^{3}$ Deri prick testi ve spesifik IgE testlerinin sonuçları genellikle uyumlu olsa da, bazı durumlarda deri prick testinin daha duyarlı olduğu düşünülmüştür (örneğin, lateks testi $)^{5}$. Özellikle bebeklerde ve DPT yapılamayan gruplarda tercih edilir. Alerjenlerle temas dönemlerinde $\operatorname{IgE}$ seviyelerinin artması ve temasın sonlandığı dönemlerde IgE seviyelerinin düşmesi bazen yanlış olarak yorumlanmasına yol açabilir. ${ }^{6}$

\footnotetext{
Alerjik Hastalıklarda Tanıda Kullanılabilecek Yardımcı Testler (In vitro)
} 
Alerjik hastalıklarda tam kan sayımı, eozinofil sayımı, total IgE düzeyi tanıda yardımcı olarak kullanılabilecek testlerdir. ${ }^{26}$

\section{SONUC}

Deri prick testinin birinci basamakta çalışan hekimlerce uygulanabilirliği hakkında genel bir görüş birliği yoktur. Testi uygulamak ve yorumlamak için eğitim almış ve oluşabilecek ciddi sistemik reaksiyonlara acil müdahale edilebilecek ortamlarda çalışan birinci basamak hekimlerince kullanılması, alerjik rinit ve hafif- orta derece astımın tanı ve yönetimini kolaylaştırır. Birinci basamakta çalışan hekimlerce DPT uygulanırken, gıda alerjisi veya şiddetli/ kontrolsüz astıma dikkat edilmelidir. $\mathrm{Bu}$ durumların varlığında hasta bir ikinci basamak kuruluşuna yönlendirilmelidir. ${ }^{2}$ Deri prick testleri hızlı ve kolay bir şekilde yapılabilir ve hastalar ve testleri yapan hemşireler tarafından iyi tolere edildiği gösterilmiştir ${ }^{27}$

Alerjik rinit, atopik astım, gida alerjisi ve böcek zehiri aşırı duyarlılığı tanısında yardımcı olabilecek serumda alerjene özgü IgE ölçümünün birinci basamakta alerjik hastalıkların tanısında kullanılması konusunda genel bir fikir birliği yoktur. Pozitif sonuçların, klinik semptomların ortaya çıkışıyla ilişskisi ciddi olarak gözden geçirilmelidir. $^{2}$

Sonuç olarak, alerjik hastalıklarda birinci basamakta uygun tanı testi seçimini etkileyen birçok faktör vardır. Birinci basamak hekimi hangi testleri kullanırsa kullansın hastanın özgeçmişine hakim olmalı, tanı testi sonuçlarını doğru yorumlayabilmeli ve elde ettiği sonuçlarla bir tedavi planı çizebilmelidir.

\section{KAYNAKLAR}

1. Sánchez-Borges $M$, Martin BL, Muraro AM, Wood RA, Agache IO, Ansotegui IJ, et al. The importance of allergic disease in public health: an iCAALL statement. World Allergy Organization Journal 2018;11(1):8. (doi: 10.1186/s40413-018-0187-2)

2. Kurt E, Metintas S, Basyigit I, Bulut I, Coskun E, et al.Prevalence and Risk Factors of Allergies in Turkey (PARFAIT): results of a multicentre cross-sectional study in adults. Eur Respir J. 2009 Apr; 33(4):724-33.

(doi: 10.1183/09031936.00082207)

3. Jutel M, Papadopoulos NG, Gronlund H, Hoffman HJ, Bohle B, Hellings P, et al. Recommendations for the allergy management in the primary care. Allergy 2014;69:708-718. (doi: 10.1111/all.12382)

4. Agache I, Ryan D, Rodriguez MR, Yusuf O, Angier E, Jutel M. Allergy management in primary care across European countries actual status. Allergy 2013 Jul;68(7):836-843.

(doi: 10.1111/all.12150)

5. Auckland Allergy Clinic. Diagnosing allergic diseases. Available from: www.allergyclinic.co.nz (Accessed Oct, 2019)

6. Coetzee O, Masekela R. A guide to performing skin-prick testing in practice: Tips and tricks of the trade. South African Family Practice 2013;55:415-419. (doi: 10.1080/20786204.2013.10874388)

7. Şekerel BE, Misırlıgil Z, Orhan F, Mungan D, -Büyüktiryaki B. Allerji Deri Testleri: Nerede, Ne Zaman, Nasıl ve Ne Kadar? Astım Allerji İmmünoloji 2017;15:1-6. (doi: 10.21911/aai.338 )

8. Cox L, Williams B, Sicherer S, Oppenheimer J, Sher L, Hamilton R, et al. Pearls and pitfalls of allergy diagnostic testing: report from the American College of Allergy, Asthma and Immunology/American Academy of Allergy, Asthma and Immunology Specific IgE Test Task Force Annals of Allergy Asthma and Immunology2008 Dec;101(6):580-592. (doi: 10.1016/S1081-1206(10)60220-7)

9. Tourlas K, Burman D. Allergy Testing. Primary Care: Clinics in Office Practice 2016;43(3):363-374.

(doi: 10.1016/j.pop.2016.04.001 )

10. Appropriate use of allergy testing in primary care- Available from:

https://bpac.org.nz/BT/2011/December/do cs/best_tests_dec2011_allergy_pages_213.pdf

11. Land MH, Wang J. Complementary and Alternative Medicine Use Among Allergy Practices: Results of a Nationwide Survey of Allergists. The Journal of Clinical Allergy and Immunology Practice 2018 Jan - Feb;6(1):99100

(doi: 10.1016/j.jaip.2017.01.017)

12. Akan A. Alerji Testleri. Aslan A, Kiper N, editörler. Çocuk Göğüs Hastalıklarında Tanı Yöntemleri. 1. Bask1: İstanbul. Probiz Ltd. Şti. (Content Ed Net Türkiye); 2016:65-77.

13. Reid MJ, Lockey RF, Turkeltaub PC, PlattsMills TA. Survey of fatalities from skin testing and immunotherapy 1985-1989. Journal of Allergy and Clinical Immunology 1993 Jul;92(1):6-15. (doi: 10.1016/0091-6749(93)90030-J)

14. Lockey RF, Benedict LM, Turkeltaub PC, Bukantz SC. Fatalities from immunotherapy (IT) and skin testing (ST). Journal of Allergy andClinical Immunology 1987 Apr; 79(4):660677.

(doi: 10.1016/S0091-6749(87)80164-1)

15. Novembre E, Bernardini R, Bertini G, Massai G, Vierucci A. Skin-prick-test-induced 
anaphylaxis. Allergy. 1995 Jun; 50(6):511513.

(doi: 10.1111/j.1398-9995.1995.tb01187.x)

16. Heinzerling L, Mari A, Bergmann KC, Bresciani M, Burbach G, Darsow U, Durham $\mathrm{S}$, et al. The skin prick test - European standards. Clinical and Translational Allergy 2013;3:3.

(doi: 10.1186/2045-7022-3-3)

17. Türk Dermatoloji Derneği- Deri prick testi http://turkdermatoloji.org.tr/media/files/file/De ri Prick testi.pdf (ET: 12.07.2019)

18. Nelson HS, Knoetzer J, Bucher B: Effect of distance between sites and region of the body on results of skin prick tests. Journal of Allergy and Clinical Immunology 1996; 97(2):596-601.

(doi: 10.1016/S0091-6749(96)70304-4)

19. Demoly P, Bousquet J, Manderscheid JC, Dreborg S, Dhivert H, Michel FB. Precision of skin prick and puncture tests with nine methods. Journal of Allergy and Clinical Immunology 1991;88(5):758-762. (10.1016/0091-6749(91)90183-O)

20. Oppenheimer J, Nelson HS: Skin testing. Ann Allergy Asthma Immunol. 2006-; 96 (2):6-12.

(doi: 10.1016/S1081-1206(10)60895-2)

21. Rhodius R, Wickens K, Cheng S, Crane J. A comparison of two skin test methodologies and allergens from two different manufacturers. Annalls of Allergy, Asthma and Immunology 2002; 88(4):374-379.

(doi:10.1016/S1081-1206(10)62367-8)

22. Konstantinou GN, Bousquet PJ, Zuberbier T, Papadopoulos NG. The longest wheal diameter is the optimal measurement for the evaluation of skin prick tests. International Archives of Allergy and Immunology2010; 151(4):343345.

(doi: 10.1159/000250443)

23. Vohlonen I, Terho EO, Koivikko A, Vanto T, Holmen A, Heinonen OP. Reproducibility of the skin prick test. Allergy 1989;44 (8):525531.

(doi: 10.1111/j.1398-9995.1989.tb04196.x)

24. Demoly P, Bousquet J, Romano A. In vivo methods for the study of allergy. Middleton's Allergy - Principles and Practice. Edited by: Adkinson NJ, Yunginger J, Busse W, Bochner B, Holgate S, Simons F. 2003, Philadelphia: Mosby, 430-439. 6

25. Crobach MJ, Hermans J, Kaptein AA, Ridderikhoff J, Petri H, Mulder JD. The diagnosis of allergic rhinitis: how to combine the medical history with the results of radioallergosorbent tests and skin prick tests. Scandinavian Journal of Primary Health Care 1998; 16(1): 30-36.

(doi: 10.1080/028134398750003377)
26. Öztürk S, Çimen M. Birinci Basamakta Atopik İnceleme $\mathrm{Ne}$ Zaman Yapılmalı? Turkiye Klinikleri J Fam Med-Special Topics 2011;2(1):17-22.

27. Sibbald B, Barnes G, Durham SR. Skin prick testing in general practice: a pilot study. Journal of Advanced Nursing 1997;26(3):537542.

(doi:0.1046/j.1365-2648.1997.t01-14-00999.x) 